\title{
Prognostic effect of serum C-reactive protein kinetics on advanced renal cell carcinoma treated with sunitinib
}

\author{
TETSUO FUJITA, KEN-ICHI TABATA, DAISUKE ISHII, KAZUMASA MATSUMOTO, \\ KAZUNARI YOSHIDA and MASATSUGU IWAMURA \\ Department of Urology, Kitasato University School of Medicine, Sagamihara, Kanagawa 252-0374, Japan
}

Received June 15, 2016; Accepted November 23, 2016

DOI: $10.3892 /$ mco.2017.1201

\begin{abstract}
C-reactive protein (CRP) is an independent prognostic factor for renal cell carcinoma (RCC). The aim of the present study was to investigate the prognostic effect of pretreatment serum CRP level and CRP kinetics on patients with advanced RCC treated with sunitinib. A total of 56 consecutive patients with advanced RCC treated with sunitinib between December, 2008 and December, 2012 were enrolled in the present study. The patients were retrospectively divided into 3 cohorts according to pretreatment serum CRP level and CRP kinetics: i) Normal CRP cohort (pretreatment CRP $\leq 0.30 \mathrm{mg} / \mathrm{dl}$ ); ii) normalized CRP cohort (pretreatment CRP $>0.30 \mathrm{mg} / \mathrm{dl}$ that normalized within 2 cycles of treatment); and iii) non-normalized CRP cohort (pretreatment CRP $>0.30 \mathrm{mg} / \mathrm{dl}$ that did not normalize after sunitinib initiation). Disease control rate, progression-free survival and overall survival times were compared for the 3 cohorts. The normal $(\mathrm{n}=17,30.4 \%)$ and the normalized $(\mathrm{n}=8,14.3 \%)$ CRP cohorts exhibited significantly better disease control rates compared with the non-normalized CRP cohort $(\mathrm{n}=31,55.4 \% ; \mathrm{P}<0.0001$ and $\mathrm{P}=0.0445$, respectively). The normal $\mathrm{CRP}$ cohort exhibited significantly longer progression-free survival compared with the non-normalized CRP cohort $(\mathrm{P}=0.0050)$. The normal and normalized CRP cohorts exhibited significantly longer overall survival compared with the non-normalized CRP cohort $(\mathrm{P}=0.0005$ and 0.0466 , respectively). Therefore, CRP kinetics and normal pretreatment CRP level are prognostic indicators in patients with advanced RCC treated with sunitinib.
\end{abstract}

\section{Introduction}

C-reactive protein (CRP), which was found to be a representative acute-phase reactant in 1930, is the most widely used

Correspondence to: Dr Tetsuo Fujita, Department of Urology, Kitasato University School of Medicine, 1-15-1 Kitasato, Minami-ku, Sagamihara, Kanagawa 252-0374, Japan

E-mail: tfujita@cd5.so-net.ne.jp

Key words: renal cell carcinoma, sunitinib, C-reactive protein, kinetics marker of systemic inflammation (1). Inflammation plays an important role during almost all stages of tumor development (2). For example, the proliferation of renal cell carcinoma (RCC) is associated with increased levels of interleukin-6 (IL-6), nuclear factor- $\mathrm{kB}$, and other inflammatory factors $(3,4)$, and the serum CRP levels were found to be correlated with the levels of proinflammatory cytokines, such as IL-6 (5). Numerous studies have demonstrated that CRP is a significant prognostic factor among patients with RCC at various stages, whether they are being treated by surgery, systemic therapy, or both (6).

Sunitinib malate (Sutent, Pfizer Inc., New York, NY, USA) is an orally administered, small-molecule, multitargeted inhibitor of tyrosine kinases (e.g., vascular endothelial growth factor receptor, platelet-derived growth factor receptor, phosphorylation of stem cell factor receptor, Fms-like tyrosine kinase-3, colony-stimulating factor-1 receptor, and RET receptor tyrosine kinases). In a phase III clinical trial including patients with advanced RCC, sunitinib achieved significantly better results compared with interferon (IFN)- $\alpha$ and is approved worldwide for the treatment of advanced $\operatorname{RCC}(7,8)$. The number of patients treated with sunitinib is increasing and, therefore, there is an urgent need to identify biomarkers that may be used to predict its efficacy.

Recent studies have revealed a prognostic role for CRP in the outcome of sunitinib treatment (9-12). Normal pretreatment CRP levels predict a higher response rate and better survival among patients undergoing sunitinib treatment $(9,11)$. However, the prognostic role of CRP kinetics after sunitinib initiation has not been investigated to date. Previous studies have demonstrated that postoperative normalization of the CRP level is associated with better prognosis in patients with localized or advanced RCC who receive nephrectomy, metastasectomy, or both (13-16). In addition, CRP kinetics has been found to be a prognostic factor for the effect of cytokine therapies $(13,15,17)$. We hypothesized that CRP kinetics may be an important predictor of the efficacy of sunitinib treatment in patients with advanced RCC.

\section{Patients and methods}

Patients and treatment. The present study was performed with the approval of the Kitasato University Medical Ethics Organization (approval no. KMEO B15-125). The 
requirement for informed consent was waived due to the retrospective nature of the analyses. Between December, 2008 and December, 2012, 56 consecutive patients with advanced RCC who were treated with sunitinib at the Department of Urology, Kitasato University Hospital (Sagamihara, Japan) were enrolled. Eligible patients had measurable tumors, metastatic or primary. All the patients underwent surgical treatment or biopsy of the primary lesion and had histologically proven RCC. The sample group comprised 40 men and 16 women, with a median age of 65 years (range, $36-80$ years) at the time of sunitinib initiation. Of the 56 patients, $53(94.6 \%)$ presented with clear-cell RCC and 3 (5.4\%) with papillary RCC. In general, sunitinib at a dose of $50 \mathrm{mg}$ was administered orally once daily in a 6-week cycle consisting of 4 weeks of treatment followed by 2 weeks without treatment. Dose reductions were permitted depending on individual tolerance.

Response and progression were assessed by the treating physician according to the Response Evaluation Criteria in Solid Tumors (RECIST), version 1.1 (https://www.eortc.be/ Recist/documents/RECISTGuidelines.pdf), determined by means of computed tomography or magnetic resonance imaging performed every 4-8 weeks. Adverse events were evaluated by means of physical examination and laboratory assessments, including hematological and serum chemistry, every 2-4 weeks during sunitinib treatment, and were graded according to the National Cancer Institute Common Terminology Criteria for Adverse Events, version 4.0 (https://evs.nci.nih.gov/ftp1/ CTCAE/CTCAE_4.03_2010-06-14_QuickReference_5x7.pdf).

Assessment of serum CRP. Serum CRP was measured by latex agglutination immunoassay using the Nanopia CRP kit (Daiichi Pure Chemicals, Tokyo, Japan). Serum CRP was assessed prior to sunitinib treatment and every 2-4 weeks during treatment. The normal cut-off value specified by the manufacturer is $0.30 \mathrm{mg} / \mathrm{dl}$ and, therefore, patients with a serum CRP level of $\leq 0.30 \mathrm{mg} / \mathrm{dl}$ were assigned to the normal CRP cohort, as previously described (9).

The patient charts were retrospectively reviewed and the patients were divided into 3 cohorts according to the pretreatment CRP level and CRP kinetics as follows: i) Normal CRP cohort (pretreatment CRP $\leq 0.30 \mathrm{mg} / \mathrm{dl}$ ); ii) normalized CRP cohort (pretreatment CRP $>0.30 \mathrm{mg} / \mathrm{dl}$ that normalized within 2 cycles of treatment); and iii) non-normalized CRP cohort (pretreatment CRP $>0.30 \mathrm{mg} / \mathrm{dl}$ that did not normalize at any point after the initiation of sunitinib treatment) (Fig. 1). Disease control rates, namely complete response, partial response (PR) and stable disease (SD), were evaluated. Non-parametric estimates of progression-free and overall survival were compared.

Statistical analysis. Analysis of variance and post hoc Fisher's protected least-significant difference test were used to evaluate differences of means between cohorts. The Chi-squared test was used to evaluate differences for categorical variables. Non-parametric estimates of survival were made by means of Kaplan-Meier curves. Survival curves were generated on the basis of progression-free and overall survival from the initiation of sunitinib treatment to the date of disease progression or death from any cause. Log-rank tests were used for statistical comparisons. The effects on survival were assessed by

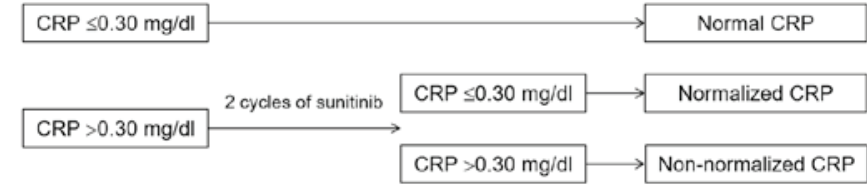

Figure 1. Flow chart of cohort definitions according to CRP kinetics. CRP, C-reactive protein.

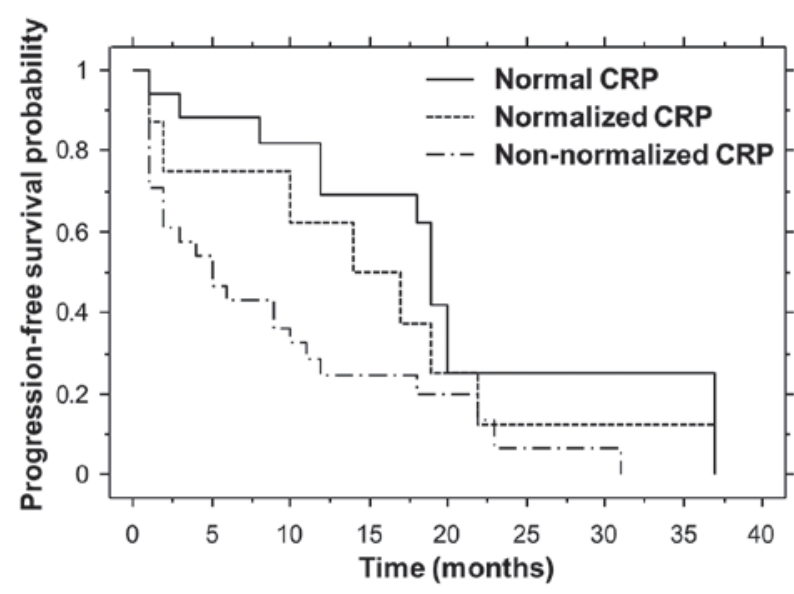

Figure 2. Kaplan-Meier estimates of progression-free survival for the three CRP cohorts. The normal CRP cohort exhibited a significantly longer progression-free survival compared with the non-normalized CRP cohort (log-rank, $\mathrm{P}=0.0050)$. CRP, C-reactive protein.

means of univariate and multivariate regression analysis using the Cox proportional hazards model. All the analyses were performed with StatView software, version 5.0 (SAS Institute, Cary, NC, USA) and differences were considered statistically significant if $\mathrm{P}<0.05$.

\section{Results}

Patient characteristics. The pretreatment characteristics of the patients are listed in Table I by CRP cohort. The median follow-up period was 15.5 months (range, 1-56 months). The normal, normalized and non-normalized CRP groups comprised $30.4,14.3$ and $55.4 \%$ of the patients, respectively. Compared with the other two cohorts, the non-normalized CRP cohort exhibited significantly higher pretreatment CRP levels $(\mathrm{P}=0.0002)$ and included a significantly higher proportion of patients with an Eastern Cooperative Oncology Group (ECOG) performance status (PS) of $\geq 1$, Memorial Sloan-Kettering Cancer Center (MSKCC) poor risk classification, no prior nephrectomy, and first-line treatment ( $\mathrm{P}=0.0051,0.0129,0.0289$ and 0.0116 , respectively). There were no statistically significant differences in any of the other pretreatment characteristics, tumor characteristics, or relative dose intensity.

Disease control rate. In the normal CRP cohort, 8 patients (47.06\%) exhibited PR to treatment and 8 patients (47.06\%) had SD, according to RECIST. In the normalized CRP cohort, 4 patients $(50.0 \%)$ exhibited PR to treatment and 2 patients (25.0\%) had SD, whereas in the non-normalized CRP cohort, 4 patients (12.9\%) exhibited PR to treatment and 7 patients 
Table I. Patient characteristics of the three CRP cohorts.

\begin{tabular}{|c|c|c|c|c|}
\hline Characteristics & Normal CRP & Normalized CRP & Non-normalized CRP & P-value \\
\hline Total patients, n (\%) & $17(30.4)$ & $8(14.3)$ & $31(55.4)$ & \\
\hline $\begin{array}{l}\text { Pretreatment serum CRP level } \\
(\text { mean } \pm \mathrm{SD} ; \mathrm{mg} / \mathrm{dl})\end{array}$ & $0.09 \pm 0.08$ & $0.80 \pm 0.72$ & $5.89 \pm 6.19$ & 0.0002 \\
\hline Gender, n (\%) & & & & 0.7682 \\
\hline Male & $13(76.5)$ & $5(62.5)$ & $22(71.0)$ & \\
\hline Female & $4(23.5)$ & $3(37.5)$ & $9(29.0)$ & \\
\hline Age, years & & & & 0.7603 \\
\hline Median & 67 & 67 & 64 & \\
\hline Range & $46-77$ & $51-\S 80$ & $36-78$ & \\
\hline Mean \pm SD & $65 \pm 9.4$ & $65.8 \pm 8.7$ & $63.5 \pm 8.8$ & \\
\hline ECOG PS, n (\%) & & & & 0.0051 \\
\hline 0 & $16(94.1)$ & $6(75.0)$ & $15(48.4)$ & \\
\hline$\geq 1$ & $1(5.9)$ & $2(25.0)$ & $16(51.6)$ & \\
\hline MSKCC risk classification, $\mathrm{n}(\%)$ & & & & 0.0129 \\
\hline Favorable & $4(23.5)$ & $2(25.0)$ & $5(16.1)$ & \\
\hline Intermediate & $13(76.5)$ & $4(50.0)$ & $11(35.5)$ & \\
\hline Poor & $0(0)$ & $2(25.0)$ & $15(48.4)$ & \\
\hline Prior nephrectomy, n (\%) & & & & 0.0289 \\
\hline Yes & $16(94.1)$ & $7(87.5)$ & $19(61.3)$ & \\
\hline No & $1(5.9)$ & $1(12.5)$ & $12(38.7)$ & \\
\hline T stage, n (\%) & & & & 0.8936 \\
\hline $\mathrm{T} 1,2$ & $8(47.1)$ & $4(50.0)$ & $13(41.9)$ & \\
\hline$\geq \mathrm{T} 3$ & $9(52.9)$ & $4(50.0)$ & $18(58.1)$ & \\
\hline Grade, n (\%) & & & & 0.3490 \\
\hline 1,2 & $11(64.7)$ & $7(87.5)$ & $15(48.4)$ & \\
\hline 3 & $5(29.4)$ & $1(12.5)$ & $10(32.2)$ & \\
\hline Prior immunotherapy, n (\%) & & & & 0.0662 \\
\hline IFN- $\alpha$ & $8(52.9)$ & $3(37.5)$ & $6(19.4)$ & \\
\hline IL-2 and IFN- $\alpha$ & $4(23.5)$ & $1(12.5)$ & $5(16.1)$ & \\
\hline Prior targeted therapy, n (\%) & & & & 0.9191 \\
\hline Sorafenib & $5(29.4)$ & $2(25.0)$ & $10(32.2)$ & \\
\hline \multicolumn{5}{|l|}{ Metastatic site, $\mathrm{n}$} \\
\hline Lung & 14 & 4 & 21 & \\
\hline Bone & 2 & 2 & 15 & \\
\hline Lymph nodes & 3 & 3 & 6 & \\
\hline Pancreas & - & 2 & 4 & \\
\hline Liver & 1 & 1 & 4 & \\
\hline Adrenal & 2 & - & 3 & \\
\hline Brain & 1 & 1 & 2 & \\
\hline Local & 1 & 1 & 1 & \\
\hline Kidney & - & 1 & 2 & \\
\hline Skin & - & - & 3 & \\
\hline Prostate & 1 & - & - & \\
\hline No. of metastatic sites, n (\%) & & & & 0.4976 \\
\hline 1 & $8(47.1)$ & $2(25.0)$ & $12(38.7)$ & \\
\hline$\geq 2$ & $8(47.1)$ & $6(75.0)$ & $18(58.1)$ & \\
\hline Treatment, n (\%) & & & & 0.0116 \\
\hline First-line & $4(23.5)$ & $3(37.5)$ & $19(61.3)$ & \\
\hline Second-line & $9(52.9)$ & $4(50.0)$ & $3(9.7)$ & \\
\hline Third-line & $4(23.5)$ & $1(12.5)$ & $9(29.0)$ & \\
\hline
\end{tabular}


Table I. Continued.

\begin{tabular}{lccc}
\hline Characteristics & Normal CRP & Normalized CRP & Non-normalized CRP \\
\hline RDI (\%) & & & 65.4 \\
Median & 61.1 & 63.0 & $16.1-100$ \\
Range & $33.3-100$ & $27.1-75$ & $62.7 \pm 22.1$ \\
Mean \pm SD & $62.5 \pm 20.0$ & $56.1 \pm 16.7$ & \\
\hline
\end{tabular}

CRP, C-reactive protein; SD, standard deviation; ECOG, Eastern Cooperative Oncology Group; PS, performance status; MSKCC, Memorial Sloan-Kettering Cancer Center; IFN, interferon; IL, interleukin; RDI, relative dose intensity.

Table II. Disease control rates by cohort.

\begin{tabular}{lcc}
\hline Cohorts & PR + SD $(\%)$ & P-value \\
\hline Normal CRP & 94.1 & $<0.0001$ \\
Normalized CRP & 75.0 & 0.0445 \\
Non-normalized CRP & 35.5 & - \\
\hline
\end{tabular}

PR, partial response; $\mathrm{SD}$, stable disease; CRP, C-reactive protein.

(22.6\%) had SD. The normal and normalized CRP cohorts exhibited significantly better disease control rates compared with the non-normalized CRP cohort $(\mathrm{P}<0.0001$ and $\mathrm{P}=0.0445$, respectively; Table II).

Progression-free survival. Non-parametric estimates of progression-free survival were analyzed by means of Kaplan-Meier curves for each cohort (Fig. 2). The median progression-free survival times for the normal, normalized and non-normalized CRP cohorts were 19.0, 14.0 and 5.0 months, respectively. The median progression-free survival for the normal CRP cohort was significantly longer compared with that for the non-normalized CRP cohort $(\mathrm{P}=0.0050)$.

Overall survival. Non-parametric estimates of overall survival were analyzed by means of Kaplan-Meier curves for each cohort (Fig. 3). The median overall survival times for the normal, normalized and non-normalized CRP cohorts were 32.0, 26.0 and 11.0 months, respectively. The median overall survival times for the normal and normalized CRP cohorts were significantly longer compared with that of the non-normalized CRP cohort ( $\mathrm{P}=0.0005$ and 0.0466 , respectively).

Cox proportional hazards model. To assess the overall prognostic significance of selected variables, univariate and multivariate Cox proportional hazards regression analyses were performed (Table III). On univariate analysis, a significantly longer overall survival was predicted by male gender [hazard ratio $(\mathrm{HR})=0.480 ; 95 \%$ confidence interval $(\mathrm{CI})$ : 0.242-0.953; $\mathrm{P}=0.0358$ ], ECOG PS $0 \quad(\mathrm{HR}=0.207 ; 95 \%$ CI: 0.096-0.447; P<0.0001), MSKCC non-poor (favorable and intermediate) risk classification $(\mathrm{HR}=0.208 ; 95 \% \mathrm{CI}$ : 0.096-0.449; $\mathrm{P}<0.0001)$ and normal plus normalized CRP (HR=0.275; 95\% CI: 0.133-0.567; $\mathrm{P}=0.0005)$.

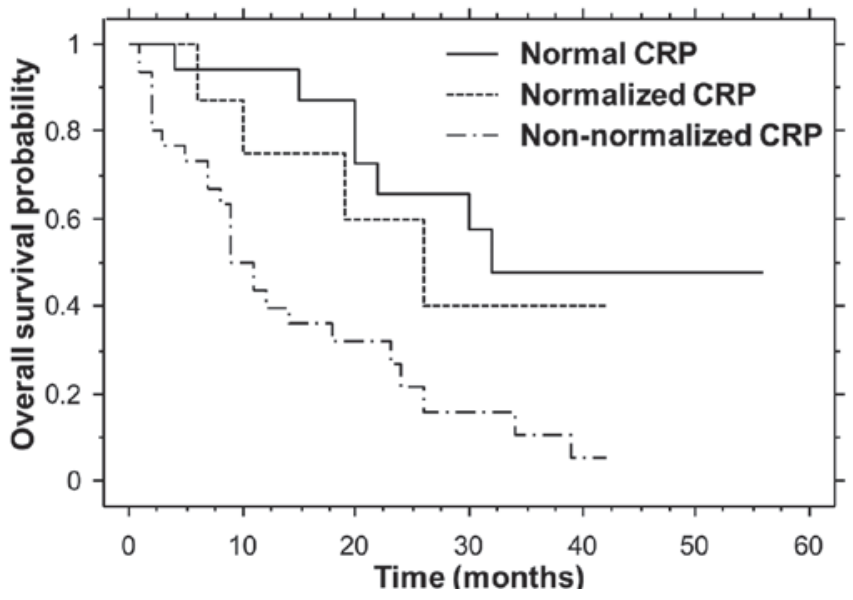

Figure 3. Kaplan-Meier estimates of overall survival for the three CRP cohorts. The normal and normalized CRP cohorts exhibited a significantly longer overall survival compared with the non-normalized CRP cohort (log-rank, $\mathrm{P}=0.0005$ and 0.0466 , respectively). CRP, C-reactive protein.

On multivariate analysis, variables associated with significantly better overall survival included male gender, ECOG PS 0, MSKCC non-poor risk classification and normal plus normalized CRP (Table III). Following adjustment for differences in these variables, normal plus normalized CRP was a predictor of better overall survival $(\mathrm{HR}=0.334 ; 95 \% \mathrm{CI}$ : 0.148-0.755; $\mathrm{P}=0.0084)$.

\section{Discussion}

CRP has been shown to be a non-specific biomarker in patients with various stages of RCC who receive surgery (13-16,18-21), immunotherapy $(13,15,17,22,23)$ and molecular-targeted therapy (9-12). CRP has a promising role in predicting survival among patients with localized and metastatic RCC. The kinetics of CRP levels in RCC was first described by Fujikawa et al in 1999 (13), in a retrospective study of 58 patients with metastatic RCC, among whom 34 had elevated pretreatment CRP ( $\geq 1.0 \mathrm{ng} / \mathrm{ml}$ ). A total of 21 patients with elevated CRP levels received cytoreductive surgery combined with postoperative immunotherapy. Patients whose postoperative nadir CRP decreased to within normal limits $(<1.0 \mathrm{ng} / \mathrm{ml})$ exhibited significantly better disease-specific survival compared with patients whose CRP remained elevated $(\mathrm{P}=0.0025)(13)$. Subsequently, Tatokoro et al (14) reported that the prognosis of patients whose CRP normalized (to $<0.5 \mathrm{mg} / \mathrm{dl}$ ) following 
Table III. Univariate and multivariate analyses with Cox proportional hazards model for predicting overall survival.

\begin{tabular}{lcrr}
\hline & \multicolumn{1}{c}{ Univariate analysis } & & Multivariate analysis \\
\cline { 2 - 3 } Variables & HR $(95 \% \mathrm{CI})$ & P-value & HR $(95 \%$ CI $)$ \\
\hline Gender (male) & $0.480(0.242-0.953)$ & 0.0358 & $0.597(0.264-1.353)$ \\
ECOG PS 0 & $0.207(0.096-0.447)$ & $<0.0001$ & $0.441(0.139-1.397)$ \\
MSKCC non-poor & $0.208(0.096-0.449)$ & $<0.0001$ & $0.795(0.230-2.750)$ \\
Normal, normalized CRP & $0.275(0.133-0.567)$ & 0.0005 & $0.334(0.148-0.755)$ \\
Prior nephrectomy (yes) & $0.552(0.255-1.195)$ & 0.1318 & 0.1642 \\
T1,2 & $1.127(0.585-2.170)$ & 0.7210 & 0.7169 \\
Grade 1,2 & $0.683(0.332-1.404)$ & 0.2993 & 0.0084 \\
Prior immunotherapy (yes) & $0.619(0.320-1.199)$ & 0.1551 & \\
Prior sorafenib (yes) & $0.916(0.449-1.868)$ & 0.8091 & \\
Single metastatic site & $0.596(0.285-1.244)$ & 0.1678 & \\
First-line treatment & $1.776(0.920-3.429)$ & 0.0868 & \\
\hline
\end{tabular}

HR, hazard ratio; CI, confidence interval; ECOG, Eastern Cooperative Oncology Group; PS, performance status; MSKCC, Memorial Sloan-Kettering Cancer Center; CRP, C-reactive protein.

cytoreductive nephrectomy and the prognosis of patients without preoperative elevated CRP were better compared with the prognosis of patients whose CRP did not normalize after surgery. These investigators concluded that CRP kinetics may predict the clinical course of patients with metastatic RCC who undergo cytoreductive nephrectomy (14). Saito et al (15) reported that CRP kinetics affect survival in patients with metastatic RCC treated with immunotherapy, metastasectomy, or both. A decrease in CRP level (to $<0.5 \mathrm{mg} / \mathrm{dl}$ ) during treatment predicts better prognosis in patients with metastatic RCC, and a prolonged period of normal CRP level is associated with prolonged survival (15). Ito et al (16) reported that non-normalization of postoperative CRP $(\geq 0.3 \mathrm{mg} / \mathrm{dl})$ strongly predicted recurrence and prognosis in 263 patients with N0M0 RCC who underwent nephrectomy. Shinohara et al (17) reported that response rate and 1-year progression-free survival were significantly higher in patients with normalized CRP compared with those in non-normalized patients treated with IFN- $\alpha$ combination therapy. The combination of natural IFN- $\alpha$ and meloxicam reduced post-treatment CRP level in nearly half of the patients in the high CRP group $(\geq 0.4 \mathrm{mg} / \mathrm{dl})$ and exhibited therapeutic efficacy in those patients (17).

We previously demonstrated that normal pretreatment CRP level is an independent prognostic factor for patients with advanced RCC treated with sunitinib; specifically, among 41 patients, the normal CRP cohort $(\leq 0.30 \mathrm{mg} / \mathrm{dl}$, $31.7 \%$ ) exhibited a significantly higher disease control rate $(\mathrm{P}=0.0022)$ and longer progression-free survival $(\mathrm{P}=0.0361)$ compared with the elevated CRP cohort ( $>0.30 \mathrm{mg} / \mathrm{dl}, 68.3 \%)$. However, $35.7 \%$ of the patients in the elevated CRP cohort still experienced clinical benefit (PR $+\mathrm{SD}$ ) from sunitinib (9). On the basis of these previous results, the present study of CRP kinetics was designed. The normalized CRP cohort comprised patients with a pretreatment CRP level of $>0.30 \mathrm{mg} / \mathrm{dl}$ that normalized (to $\leq 0.30 \mathrm{mg} / \mathrm{dl}$ ) within 2 cycles of treatment; the cohort was defined this way as most therapeutic evaluations were performed 2 cycles after the initiation of sunitinib treatment. The normal CRP cohort (CRP $\leq 0.30 \mathrm{mg} / \mathrm{dl}, 30.4 \%$ of the patients) exhibited a significantly better disease control rate, longer progression-free survival and longer overall survival $(\mathrm{P}<0.0001, \mathrm{P}=0.0050$ and $\mathrm{P}=0.0005$, respectively) compared with the non-normalized CRP cohort. The normalized CRP cohort (14.3\%) also exhibited a significantly better disease control rate and longer overall survival $(\mathrm{P}=0.0445$ and 0.0466, respectively) compared with the non-normalized CRP cohort. The multivariate analysis revealed that normal plus normalized CRP predicted better overall survival $(\mathrm{HR}=0.334$; 95\% CI: $0.148-0.755 ; \mathrm{P}=0.0084)$. There were no significant differences between the cohorts with regard to relative dose intensity of sunitinib. To the best of our knowledge, the present study is the first to describe the prognostic effect of CRP kinetics in patients with advanced RCC treated with sunitinib.

The mechanisms of CRP normalization after initiation of sunitinib have not been explained in detail to date. CRP production in the liver is strongly induced by proinflammatory cytokines, such as IL-1, tumor necrosis factor and particularly IL-6 (24). Experimental studies have demonstrated that RCC cells may produce IL-6, which is recognized as a growth promotor in RCC cells $(3,25)$. By reducing tumor volume, sunitinib treatment may reduce the total amount of IL-6 secreted by the tumor, which in turn may contribute to CRP normalization following initiation of sunitinib treatment.

The reported proportions of patients who experience CRP normalization vary between studies. For example, Tatokoro et al (14) reported that CRP decreased to normal after cytoreductive nephrectomy in $74 \%$ of patients who had elevated CRP prior to surgery, and Ito et al (16) reported that $65.8 \%$ of patients achieved CRP normalization following nephrectomy. By contrast, Saito et al (15) reported that, among patients who underwent immunotherapy, metastasectomy, or both, only $49 \%$ achieved CRP normalization. Shinohara et al (17) reported that, among patients with a high baseline CRP level, 50\% had CRP levels within the normal range following IFN- $\alpha$ combination therapy. In the present 
study, CRP normalization after initiation of sunitinib treatment was observed in only $20.5 \%$ of the patients with elevated pretreatment CRP levels. The differences between these studies may have been due to the different types of treatment that were applied.

There were potential limitations to the present study. First, this was a retrospective, single-institutional study. Second, the sample size of the present study was small, as the normalized CRP cohort only included 8 patients. However, significant results of disease control rate and overall survival were obtained and we do not consider that these limitations affected the validity of our results.

Several clinical and molecular markers predicting the outcome of sunitinib treatment have been identified to date. CRP kinetics may play an important role in predicting the outcome of sunitinib treatment and may be an informative marker to guide early changes to the chemotherapeutic agent if CRP does not decrease after the initiation of sunitinib. Another important issue is treatment selection in patients with non-normalized CRP. Further studies are required to determine the optimal treatment for the non-normalized CRP cohort.

In conclusion, pretreatment normal CRP predicted a better disease control rate, longer progression-free survival and longer overall survival in patients with advanced RCC treated with sunitinib. Post-treatment CRP normalization also predicted a better disease control rate and longer overall survival. CRP kinetics as well as pretreatment CRP level were found to be prognostic indicators in patients with advanced RCC treated with sunitinib.

\section{Acknowledgements}

The authors would like to thank Neil M. Singer for providing expert editorial assistance.

\section{References}

1. Tillett WS and Francis T: Serological reactions in pneumonia with a non-protein somatic fraction of pneumococcus. J Exp Med 52: 561-571, 1930.

2. Grivennikov SI, Greten FR and Karin M: Immunity, inflammation, and cancer. Cell 140: 883-899, 2010.

3. Koo AS, Armstrong C, Bochner B, Shimabukuro T, Tso CL, deKernion JB and Belldegrum A: Interleukin-6 and renal cell cancer: Production, regulation, and growth effects. Cancer Immunol Immunother 35: 97-105, 1992.

4. Oya M, Takayanagi A, Horiguchi A, Mizuno R, Ohtsubo M, Marumo K, Shimizu N and Murai M: Increased nuclear factor-kappa $\mathrm{B}$ activation is related to the tumor development of renal cell carcinoma. Carcinogenesis 24: 377-384, 2003.

5. Blay JY, Negrier S, Combaret V, Attali S, Goillot E, Merrouche Y, Mercatello A, Ravault A, Tourani JM, Moskovtchenko JF, et al: Serum level of interleukin 6 as a prognosis factor in metastatic renal cell carcinoma. Cancer Res 52: 3317-3322, 1992.

6. Saito K and Kihara K: Role of C-reactive protein in urological cancers: A useful biomarker for predicting outcomes. Int J Urol 20: 161-171, 2013.

7. Motzer RJ, Hutson TE, Tomczak P, Michaelson MD, Bukowski RM, Rixe O, Oudard S, Negrier S, Szczylik C, Kim ST, et al: Sunitinib versus interferon alfa in metastatic renal-cell carcinoma. N Engl J Med 356: 115-124, 2007.

8. Motzer RJ, Hutson TE, Tomczak P, Michaelson MD, Bukowski RM, Oudard S, Negrier S, Szczylik C, Pili R, Bjarnason GA, et al: Overall survival and updated results for sunitinib compared with interferon alfa in patients with metastatic renal cell carcinoma. J Clin Oncol 27: 3584-3590, 2009.
9. Fujita T, Iwamura M, Ishii D, Tabata K, Matsumoto K, Yoshida K and Baba S: C-reactive protein as a prognostic marker for advanced renal cell carcinoma treated with sunitinib. Int J Urol 19: 908-913, 2012.

10. Yasuda Y, Saito K, Yuasa T, Kitsukawa S, Urakami S, Yamamoto S, Yonese J, Takahashi S and Fukui I: Prognostic impact of pretreatment C-reactive protein for patients with metastatic renal cell carcinoma treated with tyrosine kinase inhibitors. Int J Clin Oncol 18: 884-889, 2013.

11. Beuselinck B, Vano YA, Oudard S, Wolter P, De Smet R, Depoorter L, Teghom C, Karadimou A, Zucman-Rossi J, Debruyne PR, et al: Prognostic impact of baseline serum $\mathrm{C}$-reactive protein in patients with metastatic renal cell carcinoma (RCC) treated with sunitinib. BJU Int 114: 81-89, 2014.

12. Teishima J, Kobatake K, Hayashi T, Seno Y, Ikeda K, Nagamatsu H, Hieda K, Shoji K, Miyamoto K, Inoue S, et al: Prognostic significance of C-reactive protein in patients with intermediate-risk metastatic renal cell carcinoma treated with molecular targeted therapy. Oncol Lett 8: 881-885, 2014.

13. Fujikawa K, Matsui Y, Oka H, Fukuzawa S and Takeuchi H: Serum C-reactive protein level and the impact of cytoreductive surgery in patients with metastatic renal cell carcinoma. J Urol 162: 1934-1937, 1999.

14. Tatokoro M, Saito K, Iimura Y, Fujii Y, Kawakami S and Kihara K: Prognostic impact of postoperative C-reactive protein level in patients with metastatic renal cell carcinoma undergoing cytoreductive nephrectomy. J Urol 180: 515-519, 2008.

15. Saito K, Tatokoro M, Fujii Y, Iimura Y, Koga F, Kawakami S and Kihara K: Impact of C-reactive protein kinetics on survival of patients with metastatic renal cell carcinoma. Eur Urol 55: 1145-1154, 2009.

16. Ito K, Yoshii H, Sato A, Kuroda K, Asakuma J, Horiguchi A, Sumitomo M and Asano T: Impact of postoperative C-reactive protein level on recurrence and prognosis in patients with NOMO clear cell renal cell carcinoma. J Urol 186: 430-435, 2011.

17. Shinohara N, Kumagai A, Kanagawa K, Maruyama S, Abe T, Sazawa A and Nonomura K: Multicenter phase II trial of combination therapy with meloxicam, a cox-2 inhibitor, and natural interferon-alpha for metastatic renal cell carcinoma. Jpn J Clin Oncol 39: 720-726, 2009.

18. Lamb GW, McMillan DC, Ramsey S and Aitchison M: The relationship between the preoperative systemic inflammatory response and cancer-specific survival in patients undergoing potentially curative resection for renal clear cell cancer. Br J Cancer 94: 781-784, 2006.

19. Ito K, Asano T, Yoshii H, Satoh A, Sumitomo M and Hayakawa M: Impact of thrombocytosis and C-reactive protein elevation on the prognosis for patients with renal cell carcinoma. Int J Urol 13: 1365-1370, 2006

20. Komai Y, Saito K, Sakai K and Morimoto S: Increased preoperative serum C-reactive protein level predicts a poor prognosis in patients with localized renal cell carcinoma. BJU Int 99: 77-80, 2007.

21. Karakiewicz PI, Hutterer GC, Trinh QD, Jeldres C, Perrotte P, Gallina A, Tostain J and Patard JJ: C-reactive protein is an informative predictor of renal cell carcinoma-specific mortality: A European study of 313 patients. Cancer 110: 1241-1247, 2007.

22. Atzpodien J, Royston P, Wandert T and Reitz M; DGCIN-German Cooperative Renal Carcinoma Chemo-Immunotherapy Trials Group: Metastatic renal carcinoma comprehensive prognostic system. Br J Cancer 88: 348-353, 2003.

23. Casamassima A, Picciariello M, Quaranta M, Berardino R, Ranieri C, Paradiso A, Lorusso V and Guida M: C-reactive protein: A biomarker of survival in patients with metastatic renal cell carcinoma treated with subcutaneous interleukin-2 based immunotherapy. J Urol 173: 52-55, 2005.

24. Gauldie J, Richards C, Harnish D, Lansdorp P and Baumann H: Interferon beta $2 / \mathrm{B}$-cell stimulatory factor type 2 shares identity with monocyte-derived hepatocyte-stimulating factor and regulates the major acute phase protein response in liver cells. Proc Natl Acad Sci USA 84: 7251-7255, 1987.

25. Miki S, Iwano M, Miki Y, Yamamoto M, Tang B, Yokokawa K, Sonoda T, Hirano T and Kishimoto T: Interleukin-6 (IL-6) functions as an in vitro autocrine growth factor in renal cell carcinomas. FEBS Lett 250: 607-610, 1989 